\title{
From dawn till dusk
}

Citation for published version (APA):

Hülsheger, U. R. (2016). From dawn till dusk: Shedding light on the recovery process by investigating daily change patterns in fatigue. Journal of Applied Psychology, 101(6), 905-914.

https://doi.org/10.1037/apl0000104

Document status and date:

Published: 01/06/2016

DOI:

10.1037/apl0000104

Document Version:

Publisher's PDF, also known as Version of record

Document license:
Taverne

Please check the document version of this publication:

- A submitted manuscript is the version of the article upon submission and before peer-review. There can be important differences between the submitted version and the official published version of record.

People interested in the research are advised to contact the author for the final version of the publication, or visit the DOI to the publisher's website.

- The final author version and the galley proof are versions of the publication after peer review.

- The final published version features the final layout of the paper including the volume, issue and page numbers.

Link to publication

\footnotetext{
General rights rights.

- You may freely distribute the URL identifying the publication in the public portal. please follow below link for the End User Agreement:

www.umlib.nl/taverne-license

Take down policy

If you believe that this document breaches copyright please contact us at:

repository@maastrichtuniversity.nl

providing details and we will investigate your claim.
}

Copyright and moral rights for the publications made accessible in the public portal are retained by the authors and/or other copyright owners and it is a condition of accessing publications that users recognise and abide by the legal requirements associated with these

- Users may download and print one copy of any publication from the public portal for the purpose of private study or research.

- You may not further distribute the material or use it for any profit-making activity or commercial gain

If the publication is distributed under the terms of Article $25 \mathrm{fa}$ of the Dutch Copyright Act, indicated by the "Taverne" license above, 


\title{
RESEARCH REPORT
}

\section{From Dawn Till Dusk: Shedding Light on the Recovery Process by Investigating Daily Change Patterns in Fatigue}

\author{
Ute R. Hülsheger \\ Maastricht University
}

\begin{abstract}
Although the notion that recovery is a process rather than a state lies at the heart of recovery theory, the continuous cycle of depletion and replenishment of resources itself has not yet been investigated empirically. In the present article, I therefore build on recovery theory and on evidence from chronobiological research and adopt a temporal research approach that allows investigating change trajectories in fatigue over the course of the day. Furthermore, the role of sleep quality and psychological detachment in these change trajectories is investigated. Hypotheses are tested in an experience-sampling study involving 133 employees who were asked to provide fatigue ratings 4 times a day over 5 consecutive workdays. Growth curve analyses revealed that on average fatigue decreased in the morning, reaching a nadir around midday and then increased until bedtime. Additionally, daily sleep quality explained variation in individuals' fatigue change trajectories: When sleep quality was low, next day fatigue decreased between morning and midday and then increased again until bedtime; when sleep quality was high, fatigue remained stable until midday and then increased again between the end of work and bedtime. Theoretical implications for the recovery literature and practical implications are discussed in conclusion.
\end{abstract}

Keywords: recovery process, fatigue, psychological detachment, sleep quality, change trajectories

Research in organizational psychology has identified successful recovery from work as an important driver of occupational wellbeing and health as well as motivation and performance (e.g., Binnewies, Sonnentag, \& Mojza, 2009; Hahn, Binnewies, Sonnentag, \& Mojza, 2011; Sonnentag, Binnewies, \& Mojza, 2010; Sonnentag, Mojza, Demerouti, \& Bakker, 2012). Accordingly, researchers have been seeking to shed light on the factors that facilitate recovery, including psychological detachment from work (i.e., the disengagement from work-related activities and thoughts during nonwork time), sleep, or physical and social activities after work (Fritz, Yankelevich, Zarubin, \& Barger, 2010; Rook \& Zijlstra, 2006; Sonnentag, 2001; Sonnentag, Binnewies, \& Mojza, 2008; Sonnentag \& Natter, 2004). The fundamental presumption underlying most of these studies is that recovery is a process rather than a state and can be described as the continuous cycle of depletion and replenishment of resources. This is in line with theoretical ideas and models of recovery, such as the effortrecovery model (Meijman \& Mulder, 1998; see also Zijlstra, Cropley, \& Rydstedt, 2014).

This article was published Online First March 7, 2016.

I thank Daphna Claes, Karen Dingli, Elif Ucbasaran, and Marcel Loeffen for their assistance in data collection. Furthermore, I would like to express my gratitude to Jonas Lang, Sjir Uitdewilligen and Robert Roe for advice and helpful suggestions during different stages of this research project.

Correspondence concerning this article should be addressed to Ute R. Hülsheger, Department of Work and Social Psychology, Faculty of Psychology and Neuroscience, Maastricht University, P.O. Box 616, 6200 MD Maastricht, The Netherlands. E-mail: ute.hulsheger@maastrichtuniversity.nl
Given that the idea of recovery as a cyclical process lies at the heart of recovery theory (Meijman \& Mulder, 1998), it is all the more surprising that little is known about the process of recovery itself, the daily cycle of expending and restoring mental and energetic resources as it unfolds over time. Traditional experience sampling studies have provided valuable insights into which factors are positively or negatively related to recovery-related states, such as vigor, fatigue, or need for recovery at a certain time of the day, typically in the morning or at the end of the day (e.g., Sonnentag et al., 2008; Sonnentag \& Natter, 2004; Sonnentag \& Zijlstra, 2006; Trougakos, Hideg, Cheng, \& Beal, 2014). For instance, research has documented that psychological detachment on the previous evening and sleep quality are negatively related to fatigue on the next morning at the within-person level (Sonnentag et al., 2008). These studies explain within-person day-to-day variation in morning fatigue (illustrated in Figure 1a) with psychological detachment and sleep quality. They have thus adopted a differential approach, which focuses on explaining how variation in variable A relates to variation in Variable B (Navarro, Roe, \& Artiles, 2015; Roe, 2014). Notably, the differential approach does not inform about the temporal characteristics of fatigue, about the continuous ebb and flow of fatigue over the course of the day and about the factors that influence this temporal ebb and flow. Does fatigue linearly increase during work and then start to decrease after work when individuals recover (illustrated in Figure 1b)? Does fatigue linearly increase over the entire course of the waking day and only decrease as we sleep (Figure 1c)? Or does it initially decrease until midday while employees are still refreshed and 

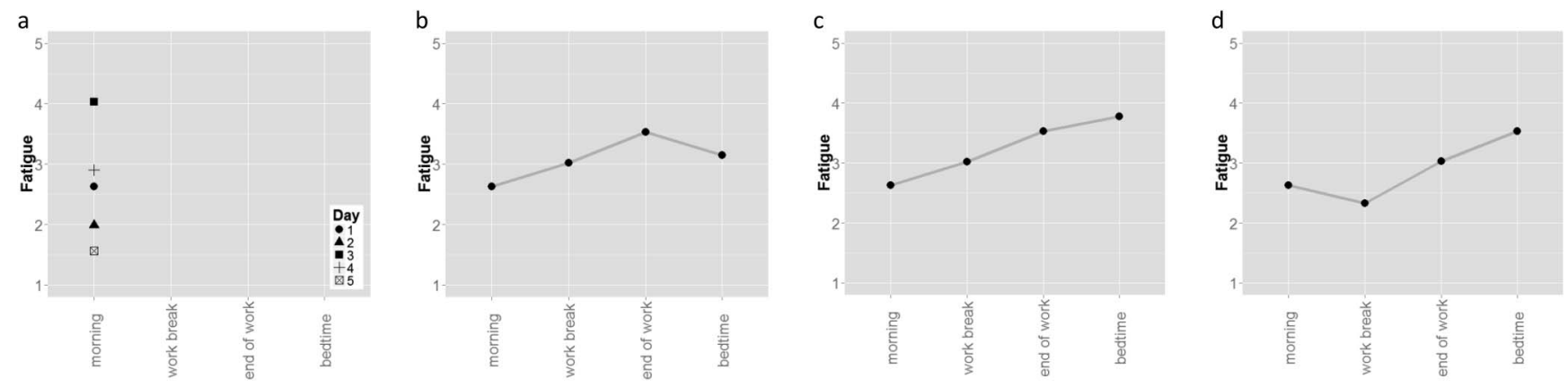

Figure 1. Panel (a) illustrates the differential approach in which within-person day to day variation in fatigue at one particular point of the day is in the focus of attention (depicted for one hypothetical person). Panels (b), (c), and (d) illustrate the temporal approach studying how fatigue may change over time within days.

become active at work and then start to increase in the afternoon (Figure 1d)?

The goal of the present study is therefore to shed light on the recovery process by studying energy depletion and replenishment as it unfolds over time. I will do so by adopting a temporal research approach (Larsen, Augustine, \& Prizmic, 2009; Navarro et al., 2015) and by studying individual-level change trajectories in fatigue over time, that is, over the course of the day. Specifically, I will (a) investigate typical individual-level change trajectories in fatigue across days and individuals and (b) study psychological detachment and sleep quality as day-level predictors of variation in individual-level change trajectories.

Adopting a temporal approach and studying the daily time course of fatigue and the factors that have an influence on it makes several contributions to the literature: First, it responds to recent calls to empirically address the dynamic process of recovery (Zijlstra et al., 2014) and thereby helps refine recovery theory. The study will reveal the typical daily time course of fatigue, informing about the level of fatigue at different times during the (work) day and when critical changes occur. Furthermore, it sheds light on the conditions that shape this time course and lead to deviations from the typical change pattern. This information is not only of theoretical but also of practical value for organizations as it may be considered in the scheduling of work tasks. For instance, while Figure 1c would suggest scheduling tasks that require a lot of attention and energy as early as possible, these tasks should be scheduled around midday if the trajectory follows Figure 1d. Second, across psychological disciplines, researchers have accentuated the need to shed light on the temporal nature of phenomena and to study psychological processes over time (Larsen et al., 2009; Ram \& Gerstorf, 2009). Similarly, it has been argued that organizational sciences need to give more explicit consideration to temporal issues (George \& Jones, 2000; Navarro et al., 2015; Ployhart \& Kim, 2013; Sonnentag, 2012) and address questions regarding the timing of effects, duration of effects and potential changes in the strength of effects over time (Ployhart \& Kim, 2013). This observation also applies to recovery research. For instance, studies have focused on rather immediate benefits of detachment and sleep quality on for example, next morning wellbeing and fatigue. Yet, these effects may fade out rather quickly and have little impact on employees' well-being and productivity during the following work period (Sonnentag \& Fritz, 2015). By studying daily fatigue change trajectories over the entire course of the day instead of momentary levels of fatigue at one particular point of the day, the present study reveals when benefits of previous day detachment and sleep quality are strongest, how long the benefits persist during the day and when they start fading out.

\section{The Temporal Approach}

Studying change processes requires a research approach that differs from traditional experience sampling studies. These have typically adopted a differential approach and have focused on within-person variation in a variable of interest, assessed at a particular point of the day (e.g., morning fatigue, depicted in Figure 1a) and have examined covariation with another variable of interest (e.g., sleep quality). Similar to cross-sectional betweenperson studies, this approach is differential in nature (Navarro et al., 2015; Roe, 2014). What makes experience-sampling studies different from cross-sectional between-person studies is that they capture not only between- but also within-person variation and typically analyze relationships at the within-person level. However, although data is collected repeatedly (i.e., across several days) within individuals, the focus is on covariation between two variables within persons at a particular time of the day. In contrast, the temporal approach focuses on variation across time and examines how phenomena unfold over time (Navarro et al., 2015; Roe, 2008, 2014). This is illustrated in Figure 1b-d depicting how fatigue may change over time, that is, here over the course of the day. The temporal approach thus requires repeated assessment of fatigue within days and a consideration of the factor time in analytical procedures.

\section{Systematic Changes in Fatigue Over the Course of the Day}

The present study focuses on fatigue, an unpleasant affective state that is characterized by low arousal, feelings of tiredness and exhaustion, and a lack of motivation to exert further effort (Sonnentag et al., 2008; Zijlstra et al., 2014). It is therefore well suited to shed light on the daily process of expending and replenishing energy. A core assumption of the present paper is that fatigue systematically changes over the course of the day. This assumption builds on evidence from chronobiological studies showing that 
fatigue-related variables like alertness, sleepiness, and performance on cognitive tasks show cyclical variation following a 24-hr rhythm (i.e., circadian rhythm) that is driven by the biological clock (Cajochen, Chellappa, \& Schmidt, 2014; Carrier \& Monk, 2000; Dijk, Duffy, \& Czeisler, 1992; Goel, Basner, Rao, \& Dinges, 2013; Johnson et al., 1992). Specifically, chronobiological research has documented that sleepiness and tiredness change over the course of the day, following a U-shaped pattern, while subjective alertness changes in an inverted U-shaped manner (Cajochen et al., 2014; Dijk et al., 1992; Gross, Gunzelmann, Gluck, Van Dongen, \& Dinges, 2006; Johnson et al., 1992). Furthermore, circadian patterns found for alertness closely parallel the body temperature cycle, suggesting that both rhythms are driven by an endogenous biological mechanism referred to as the circadian pacemaker or the "biological clock" (Dijk et al., 1992; Johnson et al., 1992). In order to be able to isolate and identify rhythmicity that is driven purely by the circadian pacemaker, these studies were conducted in the laboratory and external factors such as light conditions, sleep-wake cycle, or the amount of waking time were controlled. Although providing compelling evidence that fatiguerelated variables do systematically change over the course of the day due to an endogenous biological mechanism, these studies provide little indication as to what exact change pattern to expect under everyday working conditions that are influenced by workrelated and other zeitgebers (i.e., "timegiver"; external cues that synchronize the biological clock with the environment) such as daylight conditions or sleeping habits. ${ }^{1}$

Seeking to learn more about the ebbing and rising of fatigue in the context of work with its social zeitgebers and external influences, it is necessary to study changes in fatigue in employees' natural environment. Although they did not study fatigue directly, chronobiological studies reviewed above provide a first indication that fatigue changes systematically over the course of a normal work day, following a U-shaped pattern.

Hypothesis 1: Fatigue systematically changes over the course of the work day, following a U-shaped pattern that is characterized by an initial decline and a positive quadratic trend.

The theorizing presented above refers to typical individual-level change patterns in fatigue across individuals and days. This is depicted in Figure 2a: Only day-to-day variation in starting values of fatigue in the morning (i.e., intercept differences) is considered and fatigue change trajectories (i.e., slopes) are considered to be the same across individuals and days. Yet, it is likely that despite a general fatigue change trajectory that is observable across individuals and days, individual-level change patterns (i.e., slopes) also vary between individuals as well as between days. Figure $2 b$ illustrates day to day variability in starting values and in individuallevel change trajectories. ${ }^{2}$ Deviations in individual-level change patterns from the average change pattern may be the result of a variety of influences including social zeitgebers, differences in work circumstances, or between- and within-person differences in dealing with daily demands and stress. In the present study, the focus is on the role of two core variables from the recovery literature as predictors of systematic individual-level changes in fatigue, namely daily levels of psychological detachment and sleep quality.

\section{The Role of Psychological Detachment and Sleep Quality in Fatigue Change Trajectories}

Psychological detachment refers to "refraining from job-related activities and thoughts during nonwork time" (p. 72; Sonnentag \& Fritz, 2015). It involves not only a physical absence from work, but also the psychological disengagement from work-related feelings and thoughts when one is away from the work setting (Sonnentag \& Fritz, 2007, 2015). When employees fail to psychologically detach from work during nonwork time and keep ruminating about past or potential future stressful work demands, this will result in continued psychophysiological activation which hinders successful recovery and may result in chronic levels of fatigue and impaired well-being in the long run (Meijman \& Mulder, 1998; Sonnentag \& Fritz, 2015). Accordingly, psychological detachment plays an important role in the recovery process and this has been documented in a variety of between- and within-person studies (for an overview, see Sonnentag \& Fritz, 2015). Similarly, sleep is needed for the recovery of biological functions and helps restoring the capacity of the human brain (Gander, Graeber, \& Belenky, 2011). Furthermore individuals physically and psychologically disengage from work and take a rest from the demands of work while sleeping. Supporting this view, research has documented that individuals experience more fatigue after nights with poor sleep (Barnes, Schaubroeck, Huth, \& Ghumman, 2011; Scott \& Judge, 2006; Sonnentag et al., 2008). Taken together, these arguments support a theoretical link between psychological detachment and sleep quality with fatigue and these links have empirically been confirmed under the traditional differential approach (between and within persons). With the present work, I aim to refine knowledge about the relation between these variables and fatigue by showing that above and beyond a general effect of psychological detachment and sleep quality on fatigue, these variables have an effect on daily fatigue change trajectories.

The effort-recovery model suggests that under optimal conditions, individuals replenish their resources after work and during the night (Meijman \& Mulder, 1998). Following the reasoning described above, individuals with low psychological detachment and sleep quality do not have optimal conditions to recover and recovery may be incomplete. The literature thus suggests that individuals with incomplete recovery start with higher fatigue levels in the morning than employees who recovered well during the past evening and night. As a first step, I therefore expect to replicate previous findings that starting values of fatigue in the morning are a function of psychological detachment and sleep quality in the previous evening/night (Barnes et al., 2011; Scott \& Judge, 2006; Sonnentag et al., 2008).

\footnotetext{
${ }^{1} \mathrm{I}$ am aware of only one study that investigated systematic changes in a fatigue-related variable in the field: Kahneman, Krueger, Schkade, Schwarz, and Stone (2004) reported decreasing levels of tiredness in the morning followed by an increase in the afternoon. The study was somewhat restricted in that it relied on a purely female sample, on the retrospective assessment of fatigue at a single day, and did not statistically analyze individual-level change trajectories.

${ }^{2}$ Note that change trajectories can vary between days and between individuals. Yet, because the focus of this study is on explaining variation in fatigue change trajectories with two day-level variables (psychological detachment and sleep quality), Figure $2 \mathrm{a}$ and $2 \mathrm{~b}$ only illustrate betweenday variation for the sake of simplicity.
} 

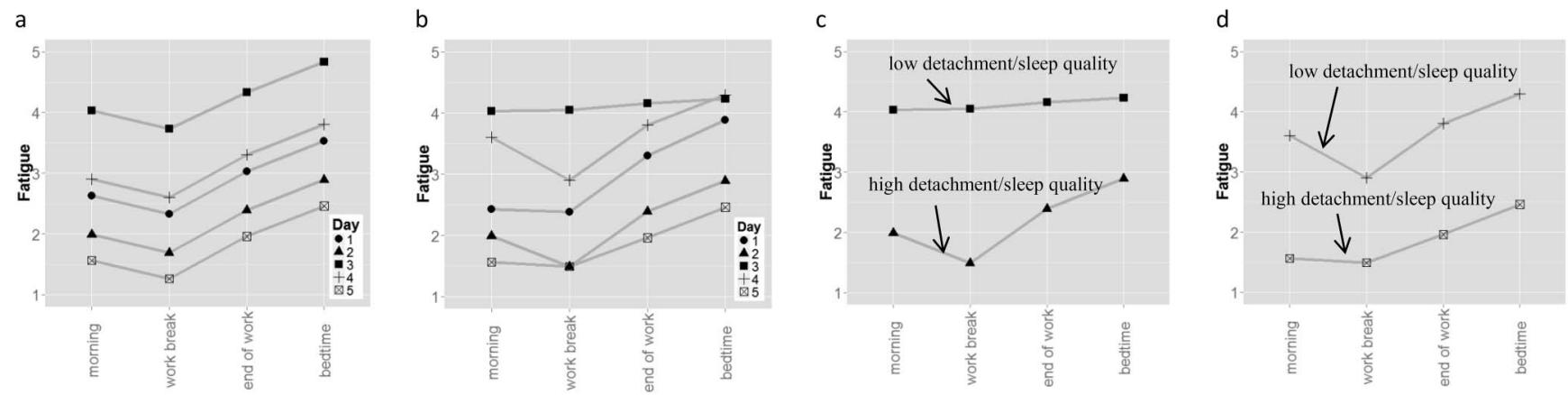

Figure 2. Panel (a) illustrates individual-level change patterns that only differ between days regarding starting values but not regarding the form of change (i.e., random intercepts, fixed slopes). Panel (b) illustrates how individual-level change patterns can also vary regarding their form of change (i.e., random intercepts and random slopes). Panel (c) illustrates Hypotheses 3a and b, and Panel (d) illustrates the competing Hypotheses 4a and b.

\begin{abstract}
Hypothesis 2: Psychological detachment (a) and sleep quality (b) predict starting-values of fatigue (i.e., intercept differences), such that morning fatigue is higher when previous evening/night psychological detachment and sleep quality was low than when it was high.
\end{abstract}

In addition, I expect that subsequent individual-level changes in fatigue (i.e., slopes) differ under good versus bad recovery conditions. Yet, theoretical considerations lead to divergent predictions regarding the exact patterns of change for individuals high versus low in psychological detachment and sleep quality. A set of contrasting hypotheses will therefore be formulated.

As argued above, chronobiological research suggests that on average fatigue changes in a U-shaped way over the course of the day. Accordingly, research on circadian rhythms in cognitive performance tasks documented a peak in performance around midday and nadirs early in the morning and late at night (Carrier \& Monk, 2000). Similarly, Kahneman and colleagues (2004) described decreases in fatigue in the morning until midday followed by a linear increase until late at night. The biological clock consequently seems to prescribe a rhythm of decreasing levels of fatigue in the first half of the day followed by an increase in the second half. Individuals who recovered well during the night may follow this biologically driven path. In contrast, when recovery was impaired by poor detachment and poor sleep quality, individuals start work in a suboptimal state. According to the effort-recovery model, they have to make additional, compensatory effort to address the demands of work, resulting in increased load reactions of the organism and chronically high levels of fatigue (Geurts \& Sonnentag, 2006; Meijman \& Mulder, 1998). Work activities performed during the first working hours should therefore be experienced as more effortful and individuals may not be so lucky to enjoy the initial morning decrease in fatigue when recovery was poor. Considering potential ceiling effects, they may experience chronic high levels of fatigue over the entire course of the day. This line of argumentation leads to the following hypotheses (see Figure $2 \mathrm{c}$ for an illustration):

Hypothesis 3a: When psychological detachment is high, next day fatigue initially declines and then increases again (i.e., initial decline and positive quadratic trend). When psychological detachment is low, fatigue remains relatively stable at a high level (i.e., weaker initial decline and weaker positive quadratic trend).

Hypothesis $3 b$ : When sleep quality is high, next day fatigue initially declines and then increases again (i.e., initial decline and positive quadratic trend). When sleep quality is low, fatigue remains relatively stable at a high level (i.e., weaker initial decline and weaker positive quadratic trend).

Yet, another line of argumentation suggests a different change pattern. When employees recovered during the previous evening/ night, they were able to replenish their resources and start the day with low fatigue levels in the morning. A floor effect may dampen the initial decrease and fatigue may gradually increase as they go back to work and invest energy to respond to the demands of work. In contrast, when recovery was poor, employees start with high fatigue levels. To address the demands of work despite of their poor recovery, they make additional compensatory effort as suggested by the effort-recovery model (Meijman \& Mulder, 1998). Yet, this compensatory effort may not lead to a stabilization of high subjective fatigue levels (as suggested in Hypotheses 3a and b), but rather to an initial decrease in subjective fatigue, due to the activation of the sympathetic nervous system that prepares the organism to address stressful situations and that results in feelings of activation. Providing some support for this view, previous research has documented steeper increases in adrenaline excretion rates in the morning under stressful conditions (Meijman, Mulder, van Dormolen, \& Cremer, 1992). As the day progresses, the compensatory effort may take its toll and subjective fatigue may increase again during the second half of the waking day. These arguments lead to the following hypothesis that competes with Hypotheses $3 \mathrm{a}$ and $3 \mathrm{~b}$ (see Figure $2 \mathrm{~d}$ for an illustration):

Hypothesis 4a: When psychological detachment is low, next day fatigue initially declines and then increases again (i.e., initial decline and positive quadratic trend). When psychological detachment is high, there is a weaker initial decline in fatigue, after which fatigue linearly increases until bedtime (i.e., weaker initial decline and weaker positive quadratic trend).

Hypothesis $4 b$ : When sleep quality is low, next day fatigue initially declines and then increases again (i.e., initial decline 
and positive quadratic trend). When sleep quality is high, there is a weaker initial decline in fatigue, after which fatigue linearly increases until bedtime (i.e., weaker initial decline and weaker positive quadratic trend).

\section{Method}

\section{Sample and Procedure}

Data reported in the present study is part of a larger data collection effort. The sample was a convenience sample consisting of Dutch native speakers, located in the Netherlands, Dutchspeaking parts of Belgium, Suriname, and Australia. Participants were recruited using different strategies, such as personal contacts, the snowballing technique, and the direct recruitment of employees at their workplaces (e.g., schools, hospitals, retail shops) or in public areas (e.g., stores, restaurants, sports clubs). Participants were approached either in person or via e-mail. No monetary compensation or other incentives were offered. Individuals were eligible when they had a regular daytime workweek and owned a smartphone on which they could complete the daily questionnaires. A total of 298 individuals expressed initial interest in the study and received an e-mail providing further information about the set-up of the study and a link to the general questionnaire, which had to be completed before participants could start with the diary part. Of these 298 individuals, 158 completed the general questionnaire. Yet, 15 of these did not start with the diary part, resulting in a response rate of $48 \%$. Because of technical issues with the online survey programming software, questionnaires of 10 participants were not sent out at the correct time points. These were therefore dropped from further analyses, resulting in a final sample of 133 individuals who completed at least one of the daily surveys. As recommended in the literature, all participants (even those with many missing values) were included in the analyses (Hox, 2002; Singer \& Willett, 2003). The final sample was predominantly female $(56.4 \%)$, had a mean age of 37 years $(S D=$ $12.8)$ and an average tenure of 7.9 years $(S D=9.6)$. The sample comprised a broad range of professions, including teachers, pharmacists, accountants, consultants, and medical practitioners.

The entire study was conducted electronically with an online survey software. It consisted of a brief general questionnaire that had to be filled in once on the computer and 4 smartphone friendly daily questionnaires that could be filled in on participants' personal smartphones. Originally, the study spanned a 7-day period, including 5 work days and 2 weekend days. For the present investigation, only the 5 work days are of interest and will be included in the analyses. In the general questionnaire, participants indicated when they typically got up, had a work break, finished work, and went to bed on a regular work day. This allowed us to send them e-mails with links to the online surveys using personalized time slots for the morning, work break, end of work and bedtime surveys. Questionnaires could be filled in for a period of 120 min after receipt of the e-mail with the link, with the exception of the bedtime questionnaire that closed at 11:59 p.m. for all participants. The majority (90\%) of participants received the morning questionnaire until 8:15 a.m., the work break questionnaire until 1:30 p.m., the end of work questionnaire until 6:30 p.m., and the bedtime questionnaire until midnight. The average time elapsed between the receipts of the questionnaires was $5 \mathrm{hr} 30 \mathrm{~min}$ (morning-work break, $S D=57 \mathrm{~min}$ ), $4 \mathrm{hr} 43 \mathrm{~min}$ (work break-end of work, $S D=1 \mathrm{hr} 13 \mathrm{~min}$ ), and $5 \mathrm{hr} 36 \mathrm{~min}$ (end of work-bedtime, $S D=$ $1 \mathrm{hr} 23 \mathrm{~min}$ ) hours.

\section{Measures}

Data collection consisted of a general survey and 20 daily surveys (four surveys per day over 5 days). The general survey assessed demographic variables such as age, gender, tenure, occupation, and times of getting up, having a work break, finishing work, and going to bed. All four diary questionnaires included a fatigue measure. In addition, the before work questionnaire included a sleep quality measure, and the bedtime questionnaire included a psychological detachment measure. All items were presented in Dutch and responses were provided on 5-point Likert scales. Cronbach's alphas are indicated in Table 1.

Fatigue. Fatigue was measured using four items from the Profiles of Mood Scales (fatigued, tired, exhausted, spent; McNair, Lorr, \& Droppelman, 1971; see also Sonnentag et al., 2008; anchors ranged from not at all to extremely).

Sleep quality. A single item from the Pittsburgh Sleep Quality Index ("How do you evaluate this night's sleep?"; Buysse, Reynolds, Monk, Berman, \& Kupfer, 1989; see also Sonnentag et al.,

Table 1

Correlations Among Study Variables

\begin{tabular}{|c|c|c|c|c|c|c|c|c|c|c|c|c|}
\hline Variable & Cronbach $\alpha$ & $M$ & $S D$ & 1 & 2 & 3 & 4 & 5 & 6 & 7 & 8 & 9 \\
\hline 1. Age & - & 37 & 12.8 & & & & & & & & & \\
\hline 2. Gender & - & - & - & $.19^{*}$ & & & & & & & & \\
\hline 3. Tenure & - & 7.92 & 9.6 & $.69^{* *}$ & .13 & & & & & & & \\
\hline 4. Fatigue morning & .87 & 1.73 & .64 & $-.30^{* *}$ & $-.29^{* *}$ & -.14 & & $.53^{* * * *}$ & $.46^{* * * *}$ & $.26^{* * * *}$ & $-.47^{* * * *}$ & .05 \\
\hline 5. Fatigue work break & .85 & 1.58 & .59 & $-.20^{*}$ & -.15 & -.13 & $.52^{* * * *}$ & & $.51^{* * * *}$ & $.37^{* * * *}$ & $-.20^{* * *}$ & -.02 \\
\hline 6. Fatigue end of work & .84 & 1.79 & .57 & $-.32^{* * * *}$ & -.12 & -.11 & $.42^{* * * *}$ & $.60^{* * * *}$ & & $.43^{* * * *}$ & $-.16^{*}$ & -.01 \\
\hline 7. Fatigue bedtime & .84 & 1.95 & .58 & $-.30^{* * *}$ & -.11 & -.15 & $.33^{* *}$ & $.54^{* * *}$ & $.60^{* * * *}$ & & -.08 & .06 \\
\hline 8. Sleep quality morning & - & 3.74 & .63 & $.19^{*}$ & .17 & .00 & $-.52^{* * * *}$ & $-.25^{* *}$ & -.11 & -.06 & & .05 \\
\hline 9. Detachment previous evening & .86 & 3.39 & .74 & -.10 & -.04 & -.09 & .05 & -.13 & -.13 & $-.20^{*}$ & -.01 & \\
\hline
\end{tabular}

Note. Correlations below the diagonal represent correlations at the between-person level $(n=103-133)$; correlations above the diagonal represent correlations at the day level $(n=197-423)$. Cronbachs $\alpha$ was calculated individually for every day and then averaged across the 5 days. Gender is coded as $1=$ female, $2=$ male.

${ }^{*} p<.05{ }^{* * *} p<.01{ }^{* * * *} p<.001$. 
2008) was used to assess sleep quality in the morning survey (anchors ranged from very bad to very good).

Psychological detachment. In the bedtime survey, psychological detachment was assessed with the respective four-item subscale of the recovery experience questionnaire (Sonnentag \& Fritz, 2007; anchors ranged from totally disagree to totally agree). An example item is "This evening, I didn't think about work at all."

\section{Analyses}

Data was analyzed with growth curve models using a random coefficient modeling framework in R (Bliese \& Ployhart, 2002; Bliese, 2006). Data had a three-level hierarchical structure with the four daily measurement occasions nested in days and in persons. I specified growth curve models, investigating change trajectories of fatigue over the course of the day and the role of sleep quality and psychological detachment on the previous evening as day-level predictors of variation in these change trajectories. Models of increasing complexity were tested, starting with an unconditional growth model including a linear and a quadratic time trend that were specified as random in days and in persons (Singer \& Willett, 2003). Model 1 informs whether and how fatigue systematically changed over the course of the day across days and individuals. Models 2 and 3 include daily psychological detachment and sleep quality as cross-level predictors of daily individual-level change trajectories in fatigue. ${ }^{3}$

\section{Results}

Intraclass coefficients revealed that $30 \%$ of the total variation in fatigue was between-person variation, while $12 \%$ and $58 \%$ was between-day, and within-day variation, respectively. The unconditional growth model (Table 2, Model 1) revealed a significant linear (coef. $=-.16, p<.001)$, and quadratic time trend (coef. $=$ $.09, p<.001$ ), indicating that across individuals and days, fatigue initially declined between the morning and the work break and then increased again, resulting in a U-shaped pattern (see Figure 3). Hypothesis 1 was therefore confirmed. Furthermore, a significant main effect for sleep quality (coef. $=-.33, p<.001$ ) emerged in Model 2, indicating that sleep quality predicted employees' starting values of fatigue and supporting Hypothesis $2 b$. In contrast, psychological detachment was unrelated to morning fatigue (coef. $=.00, p=.975$ ) and Hypothesis 2a was not supported. Models 2 and 3 further tested whether variation in individual-level changes in fatigue was a function of psychological detachment and sleep quality (Hypotheses 3 and 4). There was no significant cross-level interaction between psychological detachment and the linear or quadratic time trend. Hypothesis $3 \mathrm{a}$ or $4 \mathrm{a}$ were thus not supported. Yet, the cross-level interaction between sleep quality and the linear time trend was significant (coef. $=.18$, $p<.001$ ), indicating that the instantaneous rate of change in fatigue (i.e., between morning and work break) was a function of sleep quality: Fatigue remained relatively stable at a low level when sleep quality was high (simple slope coef. $=-.02, p=.803$ ) while it decreased significantly when sleep quality was low (simple slope coef. $=-.38, p<.001$; see Figure 4 ). The interaction between sleep quality and the positive quadratic time trend (specifying the curvature of changes in fatigue over the course of the day) was not statistically significant when applying a two-tailed test of significance (coef. $=-.03, p=.054$ ). Results thus provided partial support for Hypothesis $4 \mathrm{~b}$, while the contrasting Hypothesis $3 \mathrm{~b}$ was not confirmed.

\section{Discussion}

A core assumption in recovery research is that recovery is a process consisting of the constant waxing and waning of energetic resources. Although this idea has been echoed in the literature and has been used as a theoretical underpinning of a wealth of research, the process itself has received little research attention. Drawing on the effort-recovery model (Meijman \& Mulder, 1998) and on empirical evidence from chronobiological research, I therefore hypothesized that fatigue systematically changes over the course of the work day and that these change trajectories are influenced by employees' psychological detachment after work and sleep quality.

\section{Theoretical Implications}

Using a temporal research approach, the present study confirmed that on average fatigue changed systematically over the course of the day, decreasing in the morning, reaching its nadir around midday and then increasing again until bedtime. In addition, there was evidence for considerable variation, both in individuals' starting values of fatigue in the morning as well as in individual-level fatigue change trajectories. Both could be explained by sleep quality on the previous night while psychological detachment was not significantly related to variation in starting values or change trajectories of fatigue. Although contrary to my expectations, this finding resembles previous findings in the literature revealing that sleep quality seems to play a stronger role in day-to-day recovery than psychological detachment (Sonnentag et al., 2008; Sonnentag \& Binnewies, 2013). Previous research suggests that effects of psychological detachment on next day fatigue may be dependent on boundary conditions, such as the amount of positive and negative affect experienced during the preceding workday (Sonnentag \& Binnewies, 2013).

Perhaps the most intriguing finding emerged under conditions of low sleep quality: Although employees start the day with significantly higher fatigue levels, fatigue initially decreased during the first working hours. This result lends support to Hypothesis $4 \mathrm{~b}$ rather than the contrasting Hypothesis 3b. Accordingly, the fact that one has to function well and address work demands despite poor recovery during the night, may lead to an increased activation of the sympathetic nervous system that initially overrides the experience of fatigue and leads to a decrease in subjective fatigue until midday. In contrast, floor effects may inhibit a further decrease in fatigue when sleep quality was high and fatigue was already lowest in the morning.

\footnotetext{
${ }^{3}$ Because psychological detachment was assessed in the bedtime survey and data was only collected from Monday through Friday, no data on psychological detachment on Sunday evenings was available. Analyses in which bedtime psychological detachment is used as a predictor of fatigue change trajectories on the following day (Table 2, Model 3) therefore only include data from Tuesday through Friday. All other analyses are based on data from Monday through Friday.
} 
Table 2

Growth Curve Models Predicting Fatigue Over the Course of the Day

\begin{tabular}{lccc}
\hline \multicolumn{1}{c}{ Effects } & Model 1 & Model 2 & Model 3 \\
\hline Fixed effects & & & \\
$\quad$ Intercept & $1.70^{* * * *}(.05)$ & $1.68^{* * * *}(.04)$ & $1.61^{* * * *}(.06)$ \\
Linear time trend & $-.16^{* * * *}(.05)$ & $-.20^{* * * *}(.05)$ & $-.07(.05)$ \\
Quadratic time trend & $.09^{* * *}(.02)$ & $.10^{* * * *}(.02)$ & $.06^{* * * *}(.02)$ \\
$\quad$ Sleep quality (SQ) & & $-.33^{* * *}(.03)$ & $.00(.04)$ \\
Detachment previous evening (DET) & & $.18^{* * * *}(.05)$ & \\
$\quad$ Linear Time Trend $\times$ SQ & & $-.03^{\dagger}(.02)$ & $-.02(.05)$ \\
Quadratic Time Trend $\times$ SQ & & & $.01(.02)$ \\
$\quad$ Linear Time Trend $\times$ DET & & & .236 \\
Quadratic Time Trend $\times$ DET & .212 & .150 & .070 \\
Random effects (person level) & .071 & .059 & .006 \\
$\quad$ Intercept & .006 & .006 & .142 \\
$\quad$ Linear time trend & & .088 & .029 \\
Quadratic time trend & .138 & .031 & .012 \\
Random effects (day level) & .008 & .007 & .130 \\
$\quad$ Intercept & .003 & .186 & \\
$\quad$ Linear time trend & .211 & & \\
Quadratic time trend & & & \\
$\quad$ Residual & & & \\
\hline
\end{tabular}

Note. $\quad N$ : Model $1=1,481$ observations, 569 days, 133 persons; Model $2=1,229$ observations, 424 days, 12 persons; Model 3 = 836 observations, 288 days, 102 persons. I tested for autoregressive structure in Model 1 (Bliese, 2006), but it did not fit the data significantly better than a model including no autocorrelation.

${ }^{\dagger} p<.10 .{ }^{* * * *} p<.001$.

To date, most research has focused on immediate benefits of recovery-related variables such as psychological detachment and sleep quality, while few have considered potential effects on outcome variables in the following work period (Sonnentag \& Fritz, 2015). The present study reveals that the benefits of sleep quality persist until the next work period but it also shows that effects slowly wear off: Recovering well after work and during the night had strongest effects on fatigue experienced in the morning before starting work. Fatigue levels of the high and the low sleep quality group approximated each other over the course of the

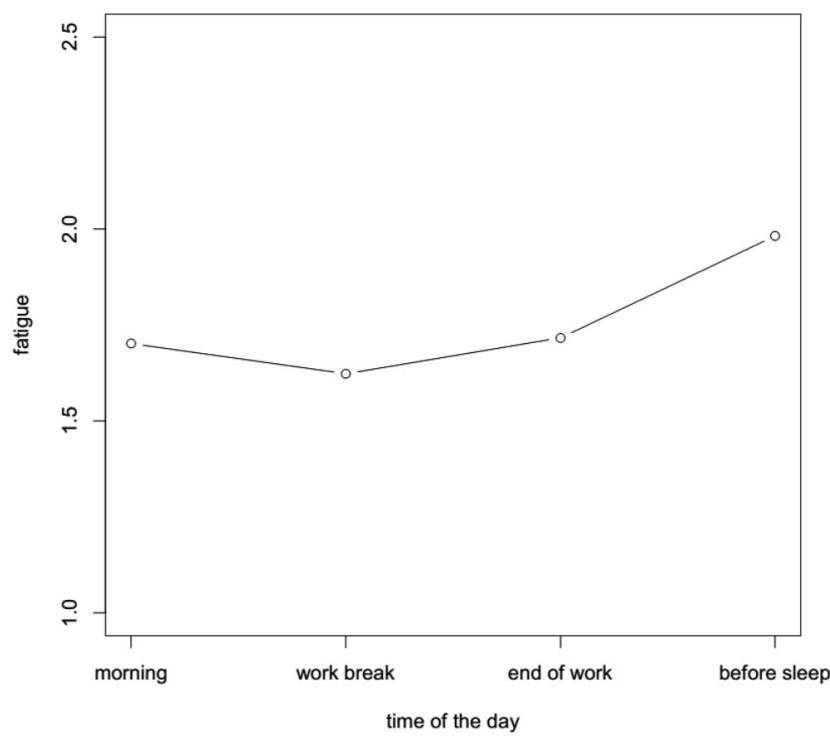

Figure 3. Average fatigue change trajectory over the course of the day. workday. Sleep quality seems to function as a buffer that shields employees against the demands of work, but the shield seems to slowly wear off as the day progresses. Supplementary analyses confirmed that differences in fatigue levels between the low versus high sleep quality group gradually decreased (morning: coef. $=-.33$, $p<.001$; work break: coef. $=-.14, p<.001$; end of work: coef. $=-.12 p<.01$ ), resulting in bedtime fatigue levels that were not significantly different from one another (coef. $=-.05, p=.173$ ). By investigating daily individual-level change trajectories in fatigue rather than focusing on explaining within-person variation in

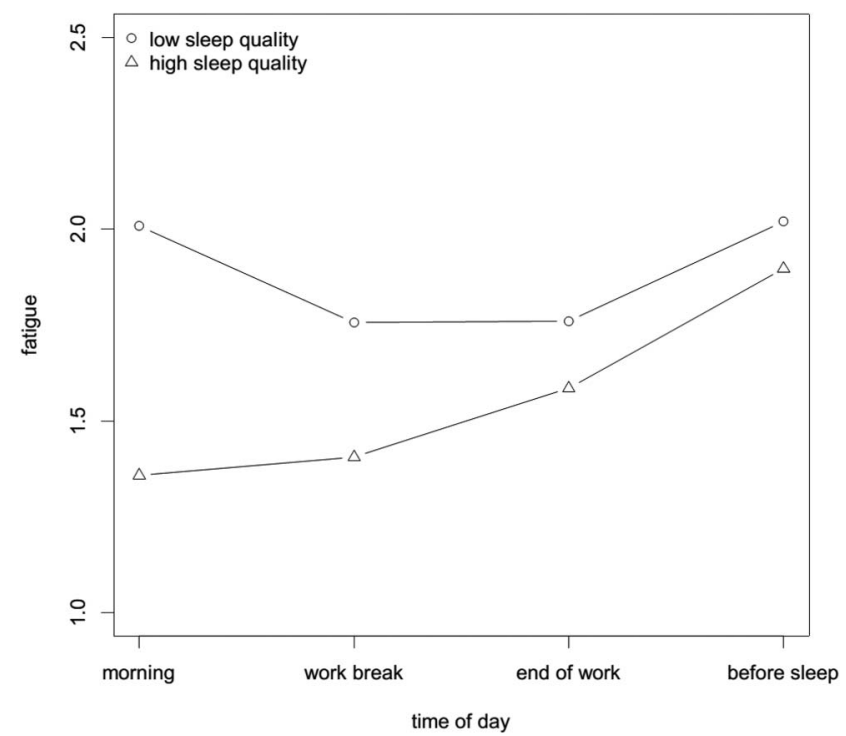

Figure 4. Changes in fatigue over the course of the day when sleep quality was low versus high. 
fatigue at one particular time during the day, the present study reveals why the effects of sleep quality on fatigue become smaller over the course of the day. As can be seen from Figure 4, the initial reduction in the effect of sleep quality on fatigue (i.e., morning vs. work break) is driven by an initial decrease in fatigue in the low sleep quality group while the high sleep quality group retained a steady low level of fatigue. In contrast, the further reduction in the effect between work break and end of work is driven by an increase in fatigue in the high sleep quality group while the low sleep quality group remained stable. This finding exemplifies the merit of adopting a temporal research approach that explicitly studies changes over time rather than differences between or within individuals at a particular point in time. It allowed addressing questions regarding the process of change, the duration of effects, and changes in the strength of effects over time (see Ployhart \& Kim, 2013) and revealed that critical changes in fatigue trajectories occur around midday, especially when previous night sleep quality was poor.

\section{Practical Implications}

As argued in the introduction, knowledge about the daily microdynamics of fatigue does not only contribute to our theoretical understanding of the recovery process, but also has direct practical implications. Accordingly, results may inform individuals and organizations about the optimal timing of work tasks that require particular concentration, attention, and energy. Findings suggest that in the absence of specific knowledge of previous night recovery, such tasks should be scheduled at a time of the work day when fatigue is typically lowest irrespective of individuals' state of recovery: around midday before taking a lunch break. Findings on differences in fatigue change trajectories further suggest that individuals may be invited to pay attention to their daily sleep quality and consider it when planning their daily work tasks: When sleep quality was good, tasks requiring concentration and attention should be conducted as early as possible while they should be scheduled around midday when sleep quality was poor. Furthermore, organizations may be well advised to provide employees with the necessary power of discretion to plan their work task autonomously and consider their previous night sleep quality in doing so.

In addition, findings further corroborated the importance of sleep quality in replenishing resources from one day to the other as sleep quality had a significant effect on fatigue throughout the entire working period (i.e., from morning till end of work). The present findings may thus encourage organizations to take measures to actively foster employees' sleep quality. Research on the effectiveness of recovery interventions is still in its infancy, but there is initial evidence that mindfulness-based interventions may be effective in doing so (Hülsheger, Feinholdt, \& Nübold, 2015).

\section{Strength, Limitations, and Avenues for Future Research}

A strength of the present research is the inclusion of more than three measurements of fatigue per day allowing to model nonlinear forms of change (Ployhart \& Kim, 2013). Without the inclusion of the work break measurement, the initial decrease in fatigue in the low sleep quality group would not have been detected and would have led to the conclusion that fatigue linearly increases from the morning till the end of work and till bedtime. Yet, more finegrained and short-lived changes such as a potential brief afterlunch dip may have been detected if more than four measurement occasions per day had been included and this is a notable limitation of this study. Another limitation is that interindividual difference variables such as morningness versus eveningness (Horne \& Ostberg, 1976), personality traits, or characteristics of the work context (e.g., work demands) have not been considered as predictors of fatigue change trajectories. Future research may explore the role of more stable between-person differences in shaping the daily waxing and waning of fatigue.

There are a number of possibilities to extend the present line of research and study other aspects of the recovery process with a change-oriented research approach. For instance, Hülsheger and colleagues (2014) studied individual-level change trajectories in psychological detachment and sleep quality over the course of the week and tried to identify predictors of these change trajectories.

\section{Conclusion}

The present study extends recovery theory by shedding light on the continuous daily process of energy depletion and replenishment. Specifically, results revealed that fatigue changes in a nonlinear way over the course of the work day: On average, fatigue slightly decreases in the first working hours and then increases again until bedtime. These change trajectories are influenced by sleep quality in the previous night, such that fatigue remains stable at a low level when sleep quality was high but starts high and initially decreases when sleep quality was low.

\section{References}

Barnes, C. M., Schaubroeck, J., Huth, M., \& Ghumman, S. (2011). Lack of sleep and unethical conduct. Organizational Behavior and Human Decision Processes, 115, 169-180. http://dx.doi.org/10.1016/j.obhdp.2011 .01 .009

Binnewies, C., Sonnentag, S., \& Mojza, E. J. (2009). Daily performance at work: Feeling recovered in the morning as a predictor of day-level job performance. Journal of Organizational Behavior, 30, 67-93. http://dx .doi.org/10.1002/job.541

Bliese, P. D. (2006). Multilevel modeling in R (2.2): A brief introduction to $R$, the multilevel package and the nlme package. Washington, DC: Walter Reed Army Institute of Research.

Bliese, P. D., \& Ployhart, R. E. (2002). Growth modeling using random coefficient models: Model building, testing, and illustrations. Organizational Research Methods, 5, 362-387. http://dx.doi.org/10.1177/ 109442802237116

Buysse, D. J., Reynolds, C. F., Monk, T. H., Berman, S. R., \& Kupfer, D. J. (1989). Pittsburgh Sleep Quality Index (PSQI). Psychiatry Research, 28, 193-213. http://dx.doi.org/10.1016/0165-1781(89)90047-4

Cajochen, C., Chellappa, S. L., \& Schmidt, C. (2014). Circadian and light effects on human sleepiness-alertness. In S. Garbarino, L. Nobili, \& G. Costa (Eds.), Sleepiness and human impact assessment (pp. 9-22). Milan, Italy: Springer. http://dx.doi.org/10.1007/978-88-470-5388-5_2

Carrier, J., \& Monk, T. H. (2000). Circadian rhythms of performance: New trends. Chronobiology International, 17, 719-732. http://dx.doi.org/10 .1081/CBI-100102108

Dijk, D.-J., Duffy, J. F., \& Czeisler, C. A. (1992). Circadian and sleep/ wake dependent aspects of subjective alertness and cognitive performance. Journal of Sleep Research, 1, 112-117. http://dx.doi.org/10 .1111/j.1365-2869.1992.tb00021.x 
Fritz, C., Yankelevich, M., Zarubin, A., \& Barger, P. (2010). Happy, healthy, and productive: The role of detachment from work during nonwork time. Journal of Applied Psychology, 95, 977-983. http://dx .doi.org/10.1037/a0019462

Gander, P., Graeber, R. C., \& Belenky, G. (2011). Fatigue risk management. In M. H. Kryger, T. Roth, \& W. C. Dement (Eds.), Principles and practice of sleep medicine. St. Louis, MO. http://dx.doi.org/10.1016/ B978-1-4160-6645-3.00068-2

George, J. M., \& Jones, G. R. (2000). The role of time in theory and theory building. Journal of Management, 26, 657-684. http://dx.doi.org/10 $.1177 / 014920630002600404$

Geurts, S. A., \& Sonnentag, S. (2006). Recovery as an explanatory mechanism in the relation between acute stress reactions and chronic health impairment. Scandinavian Journal of Work, Environment \& Health, 32, 482-492. http://dx.doi.org/10.5271/sjweh.1053

Goel, N., Basner, M., Rao, H., \& Dinges, D. F. (2013). Circadian rhythms, sleep deprivation, and human performance. Progress in Molecular Biology and Translational Science, 119, 155-190. http://dx.doi.org/10 .1016/B978-0-12-396971-2.00007-5

Gross, J. B., Gunzelmann, G., Gluck, K. A., Van Dongen, H. P. A., \& Dinges, D. F. (2006). Computational modeling of the combined effects of circadian rhythm and sleep deprivation. In Proceedings of the TwentyEighth Annual Meeting of the Cognitive Science Society (pp. 297-302). Mahwah, NJ: Erlbaum.

Hahn, V. C., Binnewies, C., Sonnentag, S., \& Mojza, E. J. (2011). Learning how to recover from job stress: Effects of a recovery training program on recovery, recovery-related self-efficacy, and well-being. Journal of Occupational Health Psychology, 16, 202-216. http://dx.doi.org/10.1037/ a0022169

Horne, J. A., \& Ostberg, O. (1976). A self-assessment questionnaire to determine morningness-eveningness in human circadian rhythms. International Journal of Chronobiology, 4, 97-110.

Hox, J. (2002). Multilevel analysis: Techniques and applications. Mahwah, MJ: Erlbaum.

Hülsheger, U. R., Feinholdt, A., \& Nübold, A. (2015). A low-dose mindfulness intervention and recovery from work: Effects on psychological detachment, sleep quality, and sleep duration. Journal of Occupational and Organizational Psychology, 88, 464-489. http://dx.doi.org/10 .1111 joop. 12115

Hülsheger, U. R., Lang, J. W. B., Depenbrock, F., Fehrmann, C., Zijlstra, F. R. H., \& Alberts, H. J. (2014). The power of presence: The role of mindfulness at work for daily levels and change trajectories of psychological detachment and sleep quality. Journal of Applied Psychology, 99, 1113-1128. http://dx.doi.org/10.1037/a0037702

Johnson, M. P., Duffy, J. F., Dijk, D.-J., Ronda, J. M., Dyal, C. M., \& Czeisler, C. A. (1992). Short-term memory, alertness and performance: A reappraisal of their relationship to body temperature. Journal of Sleep Research, 1, 24-29. http://dx.doi.org/10.1111/j.1365-2869.1992 .tb00004.x

Kahneman, D., Krueger, A. B., Schkade, D. A., Schwarz, N., \& Stone, A. A. (2004). A survey method for characterizing daily life experience: The day reconstruction method. Science, 306, 1776-1780. http://dx.doi .org/10.1126/science. 1103572

Larsen, R. J., Augustine, A. A., \& Prizmic, Z. (2009). A process approach to emotion and personality: Using time as a facet of data. Cognition and Emotion, 23, 1407-1426. http://dx.doi.org/10.1080/02699930902851302

McNair, D. M., Lorr, M., \& Droppelman, L. F. (1971). Manual for the Profile of Mood States. San Diego, CA: EdITS.

Meijman, T. F., \& Mulder, G. (1998). Psychological aspects of workload. In P. J. D. Drenth \& H. Thierry (Eds.), Handbook of work and organizational psychology: Work psychology (pp. 5-33). Hove, United Kingdom: Psychology Press.

Meijman, T. F., Mulder, H. P. G., van Dormolen, M., \& Cremer, R. (1992). Workload of driving examiners: A psychophysiological field study. In
H. Kragt (Ed), Enhancing industrial performance (pp. 245-258). London, United Kingdom: Taylor \& Francis.

Navarro, J., Roe, R. A., \& Artiles, M. I. (2015). Taking time seriously: Changing practices and perspectives in Work/Organizational Psychology. Journal of Work and Organizational Psychology, 31, 135-145.

Ployhart, R. E., \& Kim, Y. (2013). Dynamic longitudinal growth models. In J. Cortina \& R. Landis (Eds.), Frontiers of methodology in organizational research. New York, NY: Routledge.

Ram, N., \& Gerstorf, D. (2009). Time-structured and net intraindividual variability: Tools for examining the development of dynamic characteristics and processes. Psychology and Aging, 24, 778-791. http://dx.doi .org/10.1037/a0017915

Roe, R. (2008). Time in applied psychology. European Psychologist, 13 , 37-52. http://dx.doi.org/10.1027/1016-9040.13.1.37

Roe, R. A. (2014). Test validity from a temporal perspective: Incorporating time in validation research. European Journal of Work and Organizational Psychology, 23, 1-15. http://dx.doi.org/10.1080/1359432X.2013 .804177

Rook, J. W., \& Zijlstra, F. R. H. (2006). The contribution of various types of activities to recovery. European Journal of Work and Organizational Psychology, 15, 218-240. http://dx.doi.org/10.1080/ 13594320500513962

Scott, B. A., \& Judge, T. A. (2006). Insomnia, emotions, and job satisfaction: A multilevel study. Journal of Management, 32, 622-645. http:// dx.doi.org/10.1177/0149206306289762

Singer, J. D., \& Willett, J. B. (2003). Applied longitudinal data analysis. Modeling change and event occurrence. New York, NY: Oxford University Press. http://dx.doi.org/10.1093/acprof:oso/9780195152968.001 .0001

Sonnentag, S. (2001). Work, recovery activities, and individual wellbeing: A diary study. Journal of Occupational Health Psychology, 6 , 196-210. http://dx.doi.org/10.1037/1076-8998.6.3.196

Sonnentag, S. (2012). Time in organizational research: Catching up on a long neglected topic in order to improve theory. Organizational Psychology Review, 2, 361-368. http://dx.doi.org/10.1177/20413866 12442079

Sonnentag, S., \& Binnewies, C. (2013). Daily affect spillover from work to home: Detachment from work and sleep as moderators. Journal of Vocational Behavior, 83, 198-208. http://dx.doi.org/10.1016/j.jvb.2013 .03 .008

Sonnentag, S., Binnewies, C., \& Mojza, E. J. (2008). "Did you have a nice evening?" A day-level study on recovery experiences, sleep, and affect. Journal of Applied Psychology, 93, 674-684. http://dx.doi.org/10.1037/ 0021-9010.93.3.674

Sonnentag, S., Binnewies, C., \& Mojza, E. J. (2010). Staying well and engaged when demands are high: The role of psychological detachment. Journal of Applied Psychology, 95, 965-976. http://dx.doi.org/10.1037/ a0020032

Sonnentag, S., \& Fritz, C. (2007). The Recovery Experience Questionnaire: Development and validation of a measure for assessing recuperation and unwinding from work. Journal of Occupational Health Psychology, 12, 204-221. http://dx.doi.org/10.1037/1076-8998.12.3 .204

Sonnentag, S., \& Fritz, C. (2015). Recovery from job stress: The stressor-detachment model as an integrative framework. Journal of Organizational Behavior, 36, S72-S103. http://dx.doi.org/10.1002/job .1924

Sonnentag, S., Mojza, E. J., Demerouti, E., \& Bakker, A. B. (2012). Reciprocal relations between recovery and work engagement: The moderating role of job stressors. Journal of Applied Psychology, 97, 842853. http://dx.doi.org/10.1037/a0028292

Sonnentag, S., \& Natter, E. (2004). Flight attendants' daily recovery from work: Is there no place like home? International Journal of Stress Management, 11, 366-391. 
Sonnentag, S., \& Zijlstra, F. R. H. (2006). Job characteristics and off-job activities as predictors of need for recovery, well-being, and fatigue. Journal of Applied Psychology, 91, 330-350. http://dx.doi.org/10.1037/ 0021-9010.91.2.330

Trougakos, J. P., Hideg, I., Cheng, B. H., \& Beal, D. J. (2014). Lunch breaks unpacked: The role of autonomy as a moderator of recovery during lunch. Academy of Management Journal, 57, 405-421. http://dx .doi.org/10.5465/amj.2011.1072
Zijlstra, F. R. H., Cropley, M., \& Rydstedt, L. W. (2014). From recovery to regulation: An attempt to reconceptualize "recovery from work." Stress and Health, 30, 244-252. http://dx.doi.org/10.1002/smi.2604

Received May 27, 2015

Revision received February 5, 2016

Accepted February 8, 2016 